\title{
Angiotensin-(1-7) and Its Effects in the Kidney
}

\author{
Marc Dilauro and Kevin D. Burns* \\ Division of Nephrology, Departments of Medicine and Cellular and Molecular \\ Medicine, Kidney Research Centre, The Ottawa Hospital, and Ottawa Hospital \\ Research Institute, University of Ottawa \\ E-mail: mdila080@uottawa.ca; kburns@ottawahospital.on.ca
}

Received March 12, 2009; Revised June 9, 2009; Accepted June 10, 2009; Published June 30, 2009

Angiotensin-(1-7) (Ang-[1-7]) is a heptapeptide member of the renin-angiotensin system (RAS), and acts as a vasodilator and antagonist of angiotensin II (Ang II) in the vasculature. The role of Ang-(1-7) in regulating kidney function is not well understood. Within the kidneys, Ang-(1-7) is generated by angiotensin-converting enzyme 2 (ACE2)mediated degradation of Ang II, sequential cleavage of the precursor angiotensin I (Ang I) by ACE2 and ACE, or the actions of brush-border membrane peptidases on Ang I. Ang(1-7) mediates its effects via binding to kidney Mas receptors, although some actions may occur via Ang II $\mathrm{AT}_{1}$ or $\mathrm{AT}_{2}$ receptors. In vitro studies suggest that Ang-(1-7) is an intrarenal vasodilator. Ang-(1-7) has been reported to induce either natriuresis/diuresis or sodium and water retention, via modulation of sodium transporters in the proximal tubule and loop of Henle, and collecting duct water transport. In the proximal tubule, Ang-(1-7) antagonizes growth-promoting signaling pathways via activation of a protein tyrosine phosphatase, whereas in mesangial cells, Ang-(1-7) stimulates cell growth via activation of mitogen-activated protein kinases. The phenotype of the Mas gene knockout mouse suggests that Ang-(1-7)-signaling events exert cardiovascular protection by regulating blood pressure, and by limiting production of reactive oxygen species and extracellular matrix proteins. Ang-(1-7) also protects against renal injury in the renal wrap hypertension model, independent of effects on blood pressure. In diabetic nephropathy, however, the role of Ang-(1-7) on disease progression remains unclear. In summary, Ang-(1-7) and its receptor Mas have emerged as important components of the intrarenal RAS. The signaling and downstream effects of Ang-(1-7) in the kidney are complex and appear to be cell specific. The body of evidence suggests that Ang-(1-7) is protective against endothelial dysfunction or Ang II-stimulated proximal tubular injury, although the overall effects on glomerular function require further study.

KEYWORDS: renin-angiotensin system, angiotensin, ACE2, Mas receptor, proximal tubule, glomerulus 


\section{INTRODUCTION}

Angiotensin-(1-7) (Ang-[1-7]) is a biologically active heptapeptide that has been postulated to counterbalance the physiological actions of angiotensin II (Ang II) within the renin-angiotensin system (RAS)[1]. In recent years, several key findings have increased our understanding of the classical RAS and the biological significance of Ang-(1-7). For instance, angiotensin-converting enzyme 2 (ACE2) was identified as an important Ang-(1-7)-forming enzyme[2,3], and the G protein-coupled receptor Mas was discovered to be an endogenous binding site for Ang-(1-7)[4]. To date, research conducted on Ang-(1-7) has largely focused on its cardiovascular actions. However, the kidney has emerged as an important target for the actions of Ang-(1-7). In this review, we highlight recent advances in our understanding of intrarenal Ang-(1-7), and its role in kidney physiology and pathophysiology.

\section{FORMATION AND METABOLISM OF INTRARENAL ANG-(1-7)}

Ang-(1-7) is generated in the vascular endothelium[5]. Thus, in human endothelial cells, Santos et al. demonstrated local production of Ang-(1-7) from angiotensin I (Ang I) or Ang II[5]. Endothelial production of Ang-(1-7) may contribute to circulating levels and, indeed, under physiological conditions, plasma concentrations of Ang-(1-7) are in the picomolar range, comparable to the plasma levels of Ang II $6,7,8]$. Evidence for the generation of intrarenal Ang-(1-7) derives from several observations. First, intrarenal levels of Ang-(1-7) are relatively high and comparable to levels of Ang II[8]. In SpragueDawley rats, Ang-(1-7) and Ang II are present at 300 and $~ 800 \mathrm{fmol} / \mathrm{g}$ kidney tissue, respectively[8]. Second, the enzymes necessary for Ang-(1-7) formation are abundant in the kidney and have also been detected in urine[9]. Third, Ang-(1-7) is detectable in urine from human subjects[10]. Indeed, Ferrario et al. reported that untreated essential hypertensive subjects exhibit lower urinary concentrations than normotensive controls, suggesting that Ang-(1-7) may play a role in the regulation of blood pressure[10].

In the kidney, Ang-(1-7) appears to be generated from its precursor Ang I or by the degradation of Ang II[11,12]. This process is mediated by various protease enzymes including neprilysin (NEP), thimet oligopeptidase (TOP), and prolyl oligopeptidase (POP) (Fig. 1), which are located either on brush-border membranes or in the cytoplasm[13,14]. Aside from the proximal tubule, however, the contribution of more distal nephron segments to the formation of Ang-(1-7) is unclear.

ACE2 is a homologue of angiotensin-converting enzyme (ACE)[2,3] that degrades Ang II to Ang-(17) and converts Ang I to angiotensin-(1-9), which in turn may be cleaved by ACE to Ang-(1-7)[15]. Of importance, the enzymatic activity of ACE2 is not blocked by conventional ACE inhibitors[15]. ACE2 is highly expressed in the kidney and colocalizes immunohistochemically with Ang-(1-7) to the proximal tubule[16]. In rat kidney, ACE2 mRNA has been detected in all nephron segments except the thick ascending limb of the loop of Henle, with relatively high levels in the proximal straight tubule[17].

In isolated rat proximal tubular segments, Li et al. demonstrated that Ang-(1-7) is generated from Ang I in an ACE2-dependent manner[17]. However, incubation with Ang II or luminal perfusion of Ang II did not result in the generation of Ang-(1-7)[17]. Conversely, studies in rat kidney cortex and isolated sheep proximal tubules have shown that Ang-(1-7) is primarily generated via the ACE2-dependent degradation of Ang II[18,19]. Importantly, Shaltout et al. were unable to detect processing of Ang I by ACE2 in sheep proximal tubules following inhibition of ACE and neprilysin[18]. Indeed, in vitro kinetic data indicate that ACE2 catalytic efficiency is 400-fold higher with Ang II as a substrate than with Ang I[15]. Although it is difficult to reconcile these data, it is possible that differences in experimental preparations (for example, microdissected proximal tubules vs. proximal tubular preparations) may account for the discrepancies in proximal tubular processing of Ang I and Ang II. In this regard, in the C57BL/6 mouse with ACE2 gene deletion, intrarenal levels of Ang II have been found to be increased, suggesting impaired Ang II processing when ACE2 is absent[20]. Nonetheless, further studies are required to determine the relative contributions of ACE2- and non-ACE2-dependent pathways to the formation of Ang-(1-7) in proximal tubule. 


\section{Angiotensinogen}

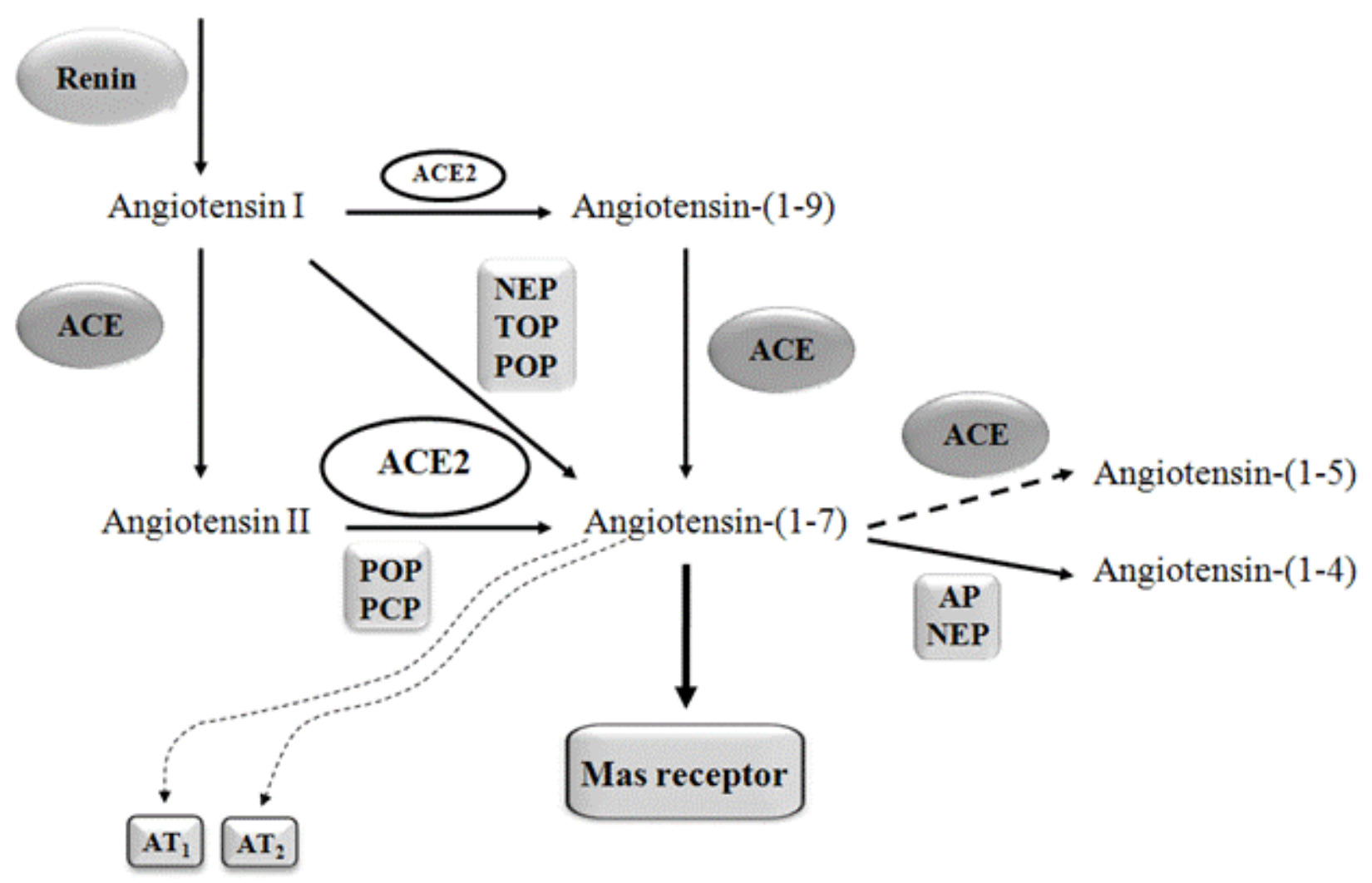

FIGURE 1. Pathways for formation and degradation of Ang-(1-7) in the kidney. Angiotensinogen is cleaved by renin to form the decapeptide Ang I, which is acted on by ACE to form the octapeptide Ang II. Ang-(1-7) is primarily generated via the ACE2-dependent metabolism of Ang II. ACE2 can also convert Ang I to Ang-(1-9), albeit at a lower efficiency, which can be metabolized by ACE to yield Ang-(1-7). Prolyl oligopeptidase (POP) and prolyl carboxypeptidase (PCP) degrade Ang II to Ang-(1-7). Alternatively, the precursor Ang I can be directly converted to Ang-(1-7) by the action of the following enzymes: neprilysin (NEP), thimet oligopeptidase (TOP), and POP. The physiological actions of Ang-(1-7) are mediated primarily by Mas receptors and to a lesser extent by $\mathrm{AT}_{1}$ and $\mathrm{AT}_{2}$ receptors (small dashed arrows). Ang-(1-7) is metabolized primarily by aminopeptidase (AP) and NEP, which convert Ang-(1-7) to the inactive peptide Ang-(1-4). ACE can also convert Ang-(1-7) to Ang-(1-5) (large dashed arrow), which is considered inactive.

ACE2 protein expression has also been detected in the glomerulus. Ye et al. reported that in the normal mouse glomerulus, ACE2 immunofluorescence colocalizes with podocyte and mesangial cell markers, but not endothelial cell markers[21]. In human kidney, however, ACE2 expression has been observed in the renal capillary endothelium[22]. Electron microscopy immunogold labeling has also localized ACE2 to podocytes[21].

In immortalized mouse podocytes, Velez et al. showed that Ang-(1-7) was the predominant peptide product after incubation with Ang II or Ang I[23]. In the presence of Ang II as a substrate, preincubation of podocytes with the ACE2 inhibitor DX-600 did not alter levels of Ang-(1-7). However, levels of Ang(1-7) were close to the lower limit of detection and therefore could not be precisely quantified. In contrast, when podocytes were incubated with Ang I, the formation of Ang-(1-7) was significantly blocked by the NEP inhibitor thiorphan. These data suggest that in podocytes, NEP plays a key role in Ang-(1-7) generation. Although ACE2 may convert Ang II to Ang-(1-7) in podocytes, the relative contribution of ACE2 to total Ang-(1-7) formation remains unclear.

Using rat renal brush-border membrane preparations, Allred et al. reported that Ang-(1-7) is rapidly hydrolyzed to angiotensin-(1-4) (Ang-[1-4]) and smaller peptide fragments[24]. Incubation with the aminopeptidase inhibitor amastatin attenuates the hydrolysis of Ang-(1-7). Similarly, combined 
incubation with amastatin and the NEP inhibitor SCH-39370 abolishes the formation of Ang-(1-4) and increases the half-life of Ang-(1-7). In addition to its metabolism to Ang-(1-4), ACE has been shown to degrade Ang-(1-7) to angiotensin-(1-5)[25,26].

\section{KIDNEY RECEPTORS FOR ANG-(1-7)}

In the mouse, deletion of the Mas proto-oncogene abolishes the intrarenal binding and functional responses to Ang-(1-7)[4]. Radioligand binding studies indicate that Mas-transfected Chinese hamster ovary $(\mathrm{CHO})$ cells bind Ang-(1-7) with high affinity $\left(\mathrm{K}_{\mathrm{d}} 0.83 \mathrm{nM}\right)$, with displacement by the Ang-(1-7) receptor antagonist A-779[4]. These findings support a role for the $\mathrm{G}$ protein-coupled Mas receptor in mediating the renal signaling effects of Ang-(1-7). Ang-(1-7) may also bind to Ang II $\mathrm{AT}_{1}$ and $\mathrm{AT}_{2}$ receptors, although radioligand binding assays suggest that these are low-affinity interactions[27]. Nonetheless, this raises the possibility that certain physiological effects of intrarenal Ang-(1-7) may be mediated by non-Mas receptors.

Using fluorescent in situ hybridization, Alenina et al. reported that Mas mRNA is abundant in mouse renal cortex[28]. Mas mRNA has also been detected in rat renal cortex and in primary cultures of rat proximal tubular cells by reverse transcription polymerase chain reaction[29]. By immunocytochemistry, the Mas receptor is expressed in the mouse afferent arteriole and in tubular epithelium, primarily on the apical surface[30]. Finally, in cultured human proximal tubular cells and human mesangial cells, Mas protein expression has been detected by immunoblot[31].

Megalin is a single-transmembrane domain receptor that belongs to the low-density lipoprotein receptor family[32]. Megalin is expressed in the brush border of the proximal tubule, where it mediates the nonspecific uptake of peptides that escape through the glomerular filtration barrier[32]. Studies in mouse renal brush-border membrane vesicles reveal that the megalin receptor binds and internalizes Ang(1-7)[33]. The biological significance of megalin-mediated uptake of Ang-(1-7) in the kidney is unclear. However, these findings suggest that megalin may serve as a major uptake pathway for Ang-(1-7) in the proximal tubule.

\section{SIGNALING PATHWAYS AND FUNCTIONS OF ANG-(1-7) IN THE KIDNEY}

\section{Regulation of Renal Hemodynamics by Ang-(1-7)}

In the nonrenal vasculature, Ang-(1-7) exerts a vasodilatory effect that involves increased production of nitric oxide (NO), prostaglandins, or endothelium-dependent hyperpolarizing relaxing factor[34,35,36]. Sampaio et al. revealed the molecular basis for the NO-releasing activity of Ang-(1-7)[37]. In human aortic endothelial cells and CHO cells stably transfected with Mas cDNA, Ang-(1-7) induced NO release by stimulating endothelial nitric oxide synthase (eNOS) and Akt phosphorylation. These effects were blocked by the Ang-(1-7) receptor antagonist A-779, suggesting involvement of Mas receptor signaling pathways.

The role of Ang-(1-7) in the regulation of renal hemodynamics is incompletely understood and data are conflicting. Van der Wouden et al. assessed the in vitro and in vivo effects of Ang-(1-7) in rat renal vasculature[38]. Although Ang-(1-7) alone did not affect vascular function, it prevented Ang II-induced vasoconstriction of isolated renal arteries in vitro. This is in agreement with studies by Ren et al., who showed that Ang-(1-7) causes afferent arteriolar dilatation, mediated by production of NO[39]. In anesthetized rats in vivo, however, Ang-(1-7) did not affect Ang II-induced afferent and efferent arteriolar constriction, nor did it alter Ang II-induced renal blood flow reduction in freely moving rats[38]. Similarly, in sodium-replete Wistar rats, Handa et al. demonstrated that Ang-(1-7) did not affect the decrease in renal blood flow induced by intrarenal bolus injection of Ang II[40]. These findings highlight the difficulty in eliciting renal hemodynamic effects of Ang-(1-7) in vivo. In this regard, since renal blood 
flow is regulated by numerous vasoconstrictor and vasodilator influences, it is possible that the vasodilatory effects of Ang-(1-7) may be masked in vivo[41].

Other studies support a regulatory role for Ang-(1-7) in the renal vasculature. Benter et al. showed that infusion of Ang-(1-7) into spontaneously hypertensive rats (SHR) normalizes systolic blood pressure[42]. In Wistar-Kyoto rats and SHR, Ang-(1-7) increases renal blood flow and inhibits Ang II pressor responses[37,43]. The latter effect is blocked by antagonism of the Mas receptor, cyclo-oxygenase inhibition, or NOS inhibition, suggesting a role for Mas-mediated release of prostaglandins and NO in the vasodilatory response to Ang-(1-7).

\section{Regulation of Renal Tubular Transport by Ang-(1-7)}

The role of Ang-(1-7) in the regulation of salt and water excretion has been the subject of several studies and, as with hemodynamic responses, the data have been difficult to reconcile. In anesthetized rats, administration of Ang-(1-7) increases urinary flow rate and sodium excretion, an effect abolished by A779[40]. Similarly, intrarenal infusion of Ang-(1-7) in dogs increases urinary excretion of water and sodium, although this is partially blocked by the $\mathrm{AT}_{1}$ receptor antagonist EXP 3174, but not by the $\mathrm{AT}_{2}$ receptor antagonist PD123319, suggesting a role for Ang-(1-7)-mediated signaling via the $\mathrm{AT}_{1}$ receptor[44].

Ang-(1-7) may limit transcellular sodium transport by regulating the activity of transporters in the proximal tubule. In cultured rabbit proximal tubular cells, Ang-(1-7) inhibits sodium flux, an effect associated with activation of phospholipase $\mathrm{A}_{2}$ [45]. In isolated rat proximal tubules, Ang-(1-7) inhibits the ouabain-sensitive $\mathrm{Na}^{+}-\mathrm{K}^{+}$-ATPase[40]. Furthermore, in isolated pig kidney inner cortical membranes, Ang-(1-7) inhibits $\mathrm{Na}^{+}$-ATPase activity, an effect that is reversed by $\mathrm{AT}_{2}$ receptor antagonism[46]. On the other hand, in isolated rat proximal straight tubules, Garcia and Garvin demonstrated that Ang-(1-7) acts through $\mathrm{AT}_{1}$ receptors to exert a biphasic effect on fluid absorption[47]. At low concentrations $\left(10^{-12} M\right)$, Ang-(1-7) increases fluid absorption $\left(\mathrm{J}_{\mathrm{v}}\right)$, whereas at high concentrations $\left(10^{-8} M\right)$, it inhibits $\mathrm{J}_{\mathrm{v}}$. Taken together, these data suggest that Ang-(1-7) causes natriuresis and diuresis via activation of Mas receptors, although there may also be involvement of $\mathrm{AT}_{1}$ and $\mathrm{AT}_{2}$ receptors.

In contrast, in water-loaded rats, Santos et al. demonstrated that infusion of Ang-(1-7) decreased urine volume, an effect reversed by Mas receptor antagonism[48]. This finding suggests that the antidiuretic effect of Ang-(1-7) is mediated, at least in part, by the Mas receptor. Joyner et al. reported that administration of Ang-(1-7) to Sprague-Dawley rats results in antidiuresis associated with up-regulation of renal aquaporin-1[49]. Chronic administration of the Mas receptor antagonist A-779 to either normal rats or SHR causes diuresis and natriuresis[50]. In virgin female rats, administration of A-779 significantly increases urine volume, suggesting that Ang-(1-7) exerts an antidiuretic effect[51]. Consistent with the previous findings, transgenic rats (TGR[A1-7]3292) that overexpress an Ang-(1-7) fusion protein, which leads to elevated plasma concentrations of Ang-(1-7), display a reduction in basal urinary flow in comparison to control rats[52]. Importantly, no significant differences in glomerular filtration rate, urinary sodium and potassium excretion, or circulating levels of vasopressin were observed between TGR(A1-7)3292 and control rats. Therefore, increased circulating levels of Ang-(1-7) appear to cause an antidiuretic effect that is independent of vasopressin release.

Aside from regulating salt and water excretion in the proximal tubule, Ang-(1-7) may modulate transport in other nephron segments. In anesthetized Munich-Wistar rats, renal micropuncture experiments revealed that Ang-(1-7) $\left(10^{-8} M\right)$ increased fluid, potassium, and sodium reabsorption in the loop of Henle[53]. This response was abolished by $\mathrm{AT}_{1}$ receptor antagonism. Notably, infusion of Ang(1-7) at physiological concentrations $\left(10^{-12}\right.$ to $\left.10^{-8} M\right)$ did not affect tubular fluid reabsorption in the proximal convoluted or distal tubule[53]. These studies therefore suggest that Ang-(1-7) increases reabsorption in the loop of Henle by an $\mathrm{AT}_{1}$ receptor-mediated mechanism.

In isolated perfused rat inner medullary collecting duct (IMCD), Santos et al. demonstrated that Ang(1-7) $\left(10^{-9} M\right)$ enhances water transport, an effect that is mediated by the Mas receptor[48]. In isolated rat 
IMCD cell suspensions, Magaldi et al. showed that Ang- $(1-7)\left(10^{-9} M\right)$ increases cAMP production[54]. This response was attenuated by Mas receptor antagonism and by pharmacological blockade of the vasopressin V2 receptor. These data provide evidence that Ang-(1-7) regulates water transport in the IMCD, possibly via a cross-talk mechanism between the Mas receptor and the vasopressin system, involving activation of adenylate cyclase.

An alternate approach to studying the effects of Ang-(1-7) on kidney water handling has been to use the nonpeptide Ang-(1-7) agonist AVE-0991. In water-loaded mice, Pinheiro et al. showed that AVE0991 caused a decrease in urine volume, associated with an increase in urine osmolality[55]. The antidiuretic effect of AVE-0991 was completely blocked by A-779, suggesting that AVE-0991 mimics the renal actions of Ang-(1-7) by binding to the Mas receptor. However, the antidiuretic effect of AVE0991 is also blocked by $\mathrm{AT}_{1}$ and $\mathrm{AT}_{2}$ receptor antagonism. The data therefore indicate that cross-talk mechanisms may exist between the Mas, $\mathrm{AT}_{1}$, and $\mathrm{AT}_{2}$ receptors that regulate water transport in the kidney.

Discrepancies between the studies regarding the role of Ang-(1-7) in the regulation of renal hemodynamics as well as salt and water excretion may be explained by differences in experimental design and use of in vitro vs. in vivo preparations. Due to the rapid degradation of Ang-(1-7) in plasma, in vivo studies that involve infusion of Ang-(1-7) may be associated with lower plasma levels than the concentrations that are utilized in vitro[38,56]. Moreover, anesthesia may complicate the interpretation of experimental findings, since it may induce significant effects on renal hemodynamics, including the lowering of vascular resistance and blood pressure[57]. Finally, it appears that although Mas receptors mediate many of the effects of Ang-(1-7) along the nephron, Ang II receptors may also be involved and could influence the net tubular effects. It is therefore evident that further studies are required to unravel the effects of Ang-(1-7) on tubular transport, since current information is difficult to reconcile into a comprehensive model.

\section{Intrarenal Ang-(1-7) and Cell Growth Pathways}

In addition to its effects on renal hemodynamics and tubular transport, Ang-(1-7) may regulate cell growth in the kidney. In rat proximal tubular cells, Ang-(1-7) inhibits Ang II-stimulated phosphorylation of three mitogen-activated protein kinases (MAPK) (p38, extracellular signal-related kinase [ERK1/2], and c-Jun N-terminal kinase [JNK]), an effect that is reversed by A-779[29]. Ang-(1-7) also partially inhibits Ang II-stimulated production of the profibrotic cytokine transforming growth factor- $\beta 1$ (TGF$\beta 1)$. The inhibitory effect of Ang-(1-7) on MAPK phosphorylation in the proximal tubule involves activation of a protein tyrosine phosphatase. In renal epithelial LLC-PK cells, Gava et al. demonstrated that Ang-(1-7) binds the Mas receptor and blocks high glucose-stimulated phosphorylation of p38 MAPK, an effect that is associated with activation of Src-homology 2-containing protein-tyrosine phosphatase-1 (SHP-1)[58]. Ang-(1-7) also inhibits high glucose-stimulated cell protein synthesis and prevents the stimulatory effect of glucose on TGF- $\beta 1$. These findings are consistent with the reported growth inhibitory properties of Ang-(1-7) on cardiac tissue. For instance, infusion of Ang-(1-7) into Sprague-Dawley rats protects against Ang II-induced cardiac myocyte hypertrophy and interstitial fibrosis[59]. Pretreatment of adult rat cardiac fibroblasts with Ang-(1-7) inhibits Ang II-induced increases in collagen synthesis and mRNA expression of growth factors[60]. Furthermore, in a rat deoxycorticosterone (DOCA)-salt model of hypertension, infusion of Ang-(1-7) prevented myocardial and perivascular fibrosis by inhibiting collagen deposition[61]. Ang-(1-7) has also been shown to inhibit the growth of cultured neonatal rat myocytes via activation of the Mas receptor[62].

The inhibitory effects of Ang-(1-7) on Ang II-mediated signaling events may involve other pathways besides direct mediation via the Mas receptor. For example, cross-talk may exist between $\mathrm{Mas}_{1} \mathrm{AT}_{1}, \mathrm{AT}_{2}$, or bradykinin B2 receptors. In this regard, Kostenis et al. showed that the Mas receptor can heterooligomerize with the $\mathrm{AT}_{1}$ receptor and inhibit the intracellular calcium mobilization effect of Ang II[63]. 
In contrast to these growth inhibitory effects, in mesangial cells, Ang-(1-7) may stimulate growth. Zimpelmann and Burns showed that Ang-(1-7) increased MAPK phosphorylation in cultured human mesangial cells, associated with stimulation of DNA synthesis, arachidonic acid release, and production of TGF- $\beta 1$ and extracellular matrix (ECM) proteins[31]. These cells were shown to express the Mas receptor and that the growth stimulatory effects of Ang-(1-7) were inhibited by A-779, but not by $\mathrm{AT}_{1}$ or $\mathrm{AT}_{2}$ receptor antagonism, and were dependent on upstream activation of p38 MAPK. Although Mas siRNA knockdown was not performed in these studies, the results strongly suggest that binding of Ang(1-7) to the Mas receptor stimulates mesangial cell growth responses. In mouse bone marrow-derived dendritic cells, Ang-(1-7) increases Ang II-mediated ERK1/2 phosphorylation, an effect blocked by A779[64]. Ang-(1-7) also potently stimulates proliferation of human cord blood hematopoietic progenitor cells, both in vitro and in vivo[65].

In summary, in the proximal tubule, Ang-(1-7) displays growth inhibitory properties and antagonizes the effects of Ang II and high glucose, whereas in mesangial cells, it appears to stimulate cell growth pathways (Fig. 2). Therefore, the overall effect of Ang-(1-7) on kidney cell growth and function is unclear and awaits further studies, including those directed at other glomerular cells and tubular segments.

A

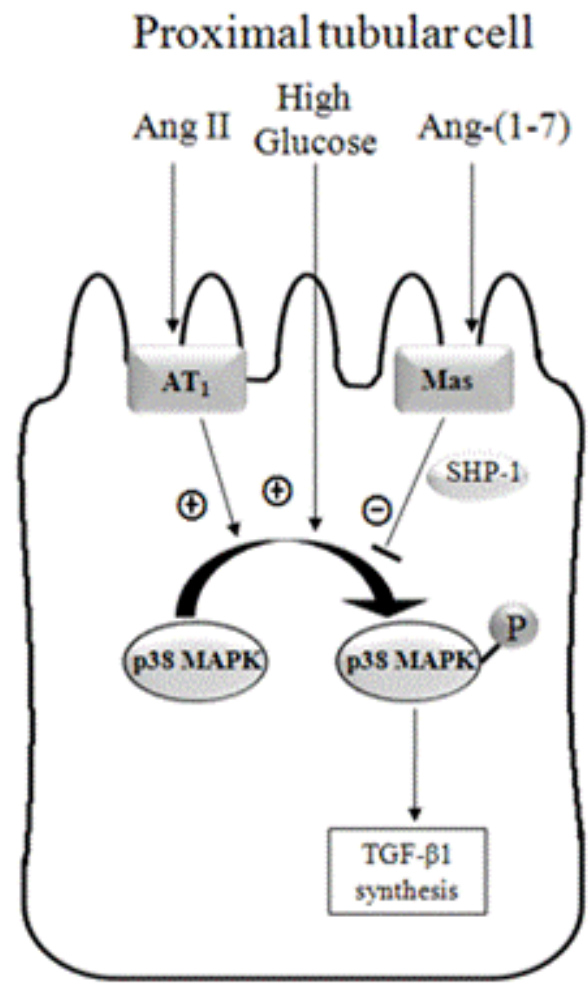

B

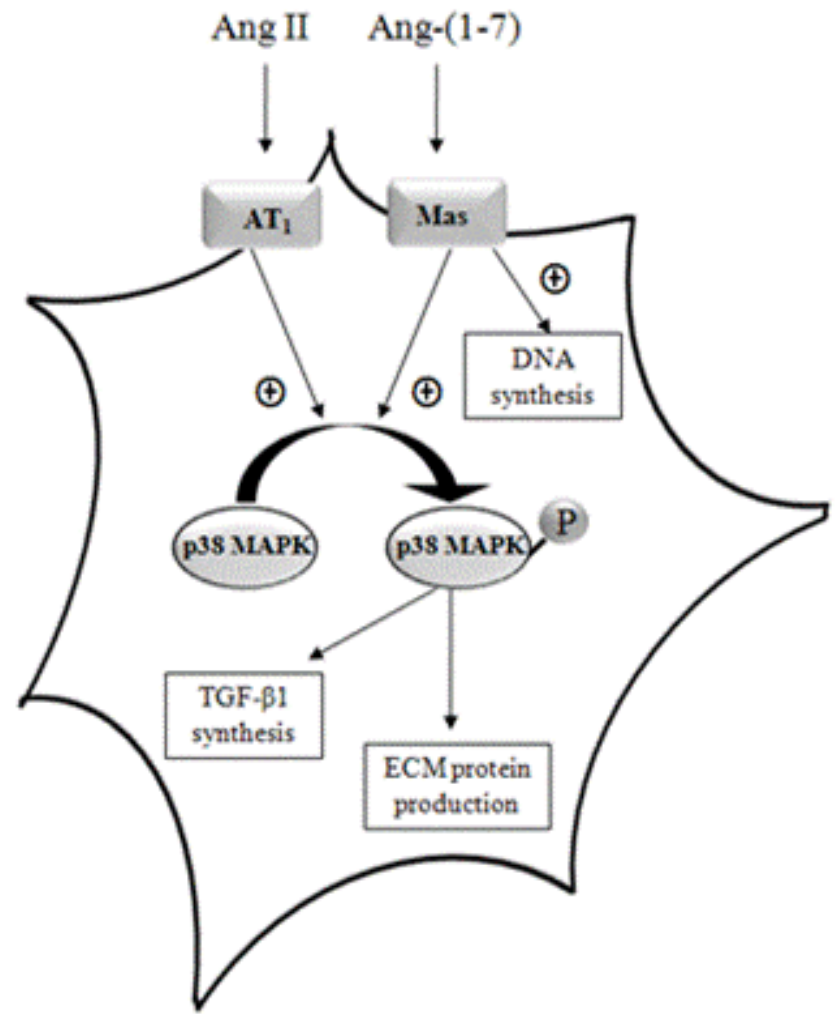

FIGURE 2. Signaling pathways for Ang-(1-7) in proximal tubule and mesangial cells. (A) In proximal tubular cells, Ang-(1-7) inhibits Ang IIor high glucose-stimulated phosphorylation of p38 MAPK via activation of SHP-1. Inhibition of p38 MAPK results in decreased synthesis of the profibrotic cytokine TGF- $\beta 1$. (B) In contrast, in mesangial cells, Ang-(1-7) stimulates cell growth pathways. Ang-(1-7) increases DNA synthesis and phosphorylation of p38 MAPK that, in turn, leads to cell arachidonic acid release, and production of TGF- $\beta_{1}$ and ECM proteins. 


\section{LESSONS FROM GENE-TARGETED MODELS}

The ACE2 gene knockout mouse may serve as a useful tool to investigate the effects of Ang-(1-7) on renal function. ACE2-deficient mice are viable, fertile, and are characterized by normal cardiac function and plasma levels of Ang II[20,66]. However, baseline blood pressures of ACE2-deficient mice vary according to genetic strain. In C57BL/6 mice, ACE2 deficiency is associated with a modest increase in blood pressure, whereas the absence of ACE2 has no effect on baseline blood pressures in 129/SvEv mice[20]. Deletion of the ACE2 gene in mice also causes late glomerulosclerosis and increased albuminuria[67]. These effects are reversed by treatment with the $\mathrm{AT}_{1}$ receptor antagonist irbesartan, suggesting that ACE2 deficiency causes renal injury via impaired degradation of Ang II and subsequent activation of $\mathrm{AT}_{1}$ receptors. However, the potential independent effect of reduced Ang-(1-7) generation on renal function in the ACE2 knockout mice has not been studied.

In this regard, the generation and characterization of Mas gene knockout mice has provided important clues on the potential role of Ang-(1-7) in normal physiology. The phenotype of the Mas knockout mouse appears to be highly dependent on strain. Mas-deficient mice on the mixed 129XC57BL/6 genetic background are healthy, grow normally, and show no obvious developmental abnormalities[68]. Indeed, these mice are normotensive and display normal plasma levels of Ang II[68]. However, Mas knockout mice on a pure C57BL/6 genetic background exhibit impaired cardiac function that is partially due to an increase in collagen expression to a profibrotic phenotype[69]. In addition, C57BL/6 Mas knockout mice exhibit a renal phenotype that is characterized by sodium and water retention, glomerular hyperfiltration, microalbuminuria, and renal fibrosis[70]. Interestingly, the renal phenotype of the Mas knockout mouse is associated with up-regulation of renal $\mathrm{AT}_{1}$ receptors. Thus, it is possible that the phenotype of the Mas gene knockout mouse may at least partly be due to increased $\mathrm{AT}_{1}$ receptor signaling activity, in addition to loss of Ang-(1-7) action. In contrast to these studies, Esteban et al. recently reported that C57BL/6 mice with Mas gene deletion had attenuated renal injury in the unilateral ureteral obstruction (UUO) and renal ischemia/reperfusion (I/R) models of renal injury[71]. Thus, Mas deficiency resulted in inhibition of $\mathrm{NF}-\mathrm{KB}$ activation and reduced levels of cytokines, suggesting that blockade of Mas signaling events may prevent renal inflammation.

Mas-deficient mice on the FVB/N genetic background display a cardiovascular phenotype that is characterized by increased arterial blood pressure, lower eNOS expression, decreased NO production, and impaired endothelial function, compared to wild-type mice[72]. In addition, the NADPH oxidase catalytic subunit gp91(phox) protein is expressed at a higher level in Mas-deficient mice compared to wild-type, whereas superoxide dismutase and catalase activities are reduced[72]. Taken together, these data suggest that Ang-(1-7)-dependent signaling events that are mediated by Mas receptors may exert cardiovascular and renal protection by regulating blood pressure, limiting production of reactive oxygen species, and preventing the synthesis of ECM proteins. However, Mas-dependent signaling events appear to promote renal inflammation and thus could potentially exacerbate the progression of renal injury.

\section{ANG-(1-7) AND DIABETIC NEPHROPATHY}

Diabetic nephropathy is the most common cause of end-stage renal disease, and is associated with activation of the intrarenal RAS and increased production of intrarenal Ang II, which mediates progressive nephron injury via the promotion of growth factors, inflammatory cytokines, and glomerular and interstitial fibrosis[73,74]. The effect of ACE2 on the development of diabetic nephropathy has been the subject of several studies and data support a renoprotective role. Renal expression of ACE2 is downregulated in murine models of diabetes and in diabetic patients[19,21,75,76,77]. Pharmacological inhibition of ACE2 in streptozotocin (STZ)-induced diabetic mice increases albuminuria and glomerular ECM expansion[78]. These effects are associated with increased ACE expression in glomeruli and renal vessels. Thus, in diabetic nephropathy, the combination of increased ACE expression and inhibition of ACE2 could augment Ang II production, leading to accelerated glomerular injury. Similarly, Wong et al. 
demonstrated that genetic deletion of the ACE2 gene accelerates diabetic renal injury[79]. ACE2 knockout mice were crossed with Akita mice, a model of type I diabetes mellitus. Diabetic ACE2 knockout mice (Ace $2^{-/ y} \mathrm{Ins} 2^{\mathrm{WT} / \mathrm{C} 96 \mathrm{Y}}$ ) exhibit increased albuminuria, mesangial matrix scores, and glomerular basement membrane thickening compared to diabetic control mice. Treatment of diabetic ACE2 knockout mice with the $\mathrm{AT}_{1}$ receptor antagonist irbesartan reduced albuminuria. Therefore, a deficiency in renal ACE2 activity may accelerate diabetic kidney injury via impaired degradation of Ang II and increased activation of $\mathrm{AT}_{1}$ receptors. However, the independent role of impaired Ang-(1-7) generation in contributing to the phenotype in diabetic ACE2 knockout mice remains unclear.

In this regard, Benter et al. reported a renoprotective role for Ang-(1-7) in the development of diabetic nephropathy[80,81]. Thus, administration of Ang-(1-7) to STZ-induced diabetic male rats reduced proteinuria and restored vascular reactivity in isolated renal artery segments[81]. Similarly, treatment of STZ-induced diabetic SHR with Ang-(1-7) attenuated NAPDH oxidase activation, diminished proteinuria, and decreased the diabetes-induced increase in renal vascular responsiveness to endothelin-1, norepinephrine, and Ang II[80].

In contrast, Shao et al. showed that chronic infusion of Ang-(1-7) to STZ-diabetic male rats accelerates renal injury[82]. Ang-(1-7) increased proteinuria as well as TGF- $\beta 1 \mathrm{mRNA}$ and protein levels in the diabetic kidney, when compared to untreated diabetic rats. It is possible that differences in rodent strain and age, as well as the dose of Ang-(1-7) and length of treatment, could contribute to the discrepancies between these studies. Moreover, the cell-specific signaling pathways associated with Ang(1-7) in the kidney could play a role in this variable response.

\section{ANG-(1-7) AND HYPERTENSION}

In male SHR treated with the NO synthesis inhibitor NG-nitro-L-arginine methyl ester (L-NAME), Ang(1-7) attenuates the elevation in mean arterial pressure[80]. This response is prevented by coadministration of indomethacin, a nonselective inhibitor of cyclo-oxygenase 1 and 2, suggesting that Ang-(1-7) may prevent development of hypertension via a prostaglandin-dependent vasodilatory pathway. In contrast, in rats with DOCA-induced hypertension, chronic infusion of Ang-(1-7) had no effect on blood pressure or cardiac hypertrophy, but significantly reduced collagen deposition in the heart[61]. Similarly, in rats chronically infused with Ang II, Ang-(1-7) infusion reduced myocyte hypertrophy and myocardial fibrosis, without significantly affecting blood pressure[59]. Thus, Ang-(1-7) appears to induce cardiac remodeling changes independent of effects on blood pressure.

Gender may play a key role in determining the renal effects of Ang-(1-7) in hypertension. In female Sprague-Dawley rats, Ji et al. utilized the renal wrap (RW) model of hypertension to investigate the role of Ang-(1-7) in the progression of hypertensive renal disease[83]. In RW ovariectomized (RW-OVX) rats, renal cortical ACE2 activity and protein were down-regulated by 31 and $30 \%$, respectively. These effects were prevented by treatment with estrogens. In addition, RW-OVX rats exhibited reduced ACE2 activity and greater tubulointerstitial fibrosis and glomerulosclerosis than RW rats. Infusion of Ang-(1-7) into RW-OVX rats prevented the exacerbating effect of ovariectomy on the degree of renal injury induced by renal wrap hypertension. Importantly, the renal protective effects associated with infusion of Ang-(17) were not attributable to changes in mean arterial pressure, heart rate, body weight, or ACE2 activity. Ovariectomy increases the activity of NADPH oxidase in RW hypertension and Ang-(1-7) inhibits renal NAPDH oxidase activity in diabetic SHR[80]. Thus, Ang-(1-7) may prevent renal injury by attenuating renal superoxide formation induced by ovariectomy. These findings suggest that estrogens cause upregulation of renal ACE2 and that increased intrarenal synthesis of Ang-(1-7) may protect against hypertensive renal disease. In the congenic mRen2 rat, Pendergrass et al. showed that females have higher ratios of renal Ang-(1-7) to Ang II compared to males, suggesting that sex differences in the renal RAS could account for the higher blood pressures in males[6].

In both rats and humans, chronic treatment with either $\mathrm{ACE}$ inhibitors or $\mathrm{AT}_{1}$ receptor blockers increases plasma levels of Ang-(1-7) (5- to 25-fold)[84,85,86,87]. ACE inhibition contributes to increased 
plasma levels of Ang-(1-7) via increased availability of Ang I and inhibition of Ang-(1-7) metabolism. Antagonism of the $\mathrm{AT}_{1}$ receptor increases Ang-(1-7) levels, presumably by increasing plasma levels of Ang II, which can be converted to Ang-(1-7) by ACE2.

This observation raises the possibility that Ang-(1-7) may contribute to the antihypertensive effects associated with $\mathrm{ACE}$ inhibition or $\mathrm{AT}_{1}$ receptor blockade. In SHR, coadministration of Ang-(1-7) with the $\mathrm{AT}_{1}$ receptor antagonist candesartan caused a marked reduction in mean arterial pressure[88]. This effect was reversed by $\mathrm{AT}_{2}$ receptor blockade, suggesting that $\mathrm{AT}_{1}$ receptor antagonism uncovers an $\mathrm{AT}_{2}$ receptor-mediated vasodilatory response to Ang-(1-7). In SHR treated with lisinopril and losartan, Iyer et al. showed that administration of a monoclonal antibody against Ang-(1-7) caused significant elevations in mean arterial pressure, suggesting that Ang-(1-7) contributes to the antihypertensive effect of combined $\mathrm{ACE}$ inhibition and $\mathrm{AT}_{1}$ receptor blockade[89]. In SHR, acute inhibition of Ang-(1-7) formation (via the use of two different NEP inhibitors) increased blood pressures approximately $20 \%$ above baseline, suggesting that Ang-(1-7) exerts a vasodilatory effect[90].

Increased ACE2 activity and subsequent formation of Ang-(1-7) may protect against the development of hypertension. Rentzsch et al. generated transgenic rats (TGR[SM22ACE2]) on a spontaneously hypertensive stroke-prone (SHRSP) genetic background that expressed the human ACE2 gene in vascular smooth muscle cells[91]. TGR(SM22ACE2) rats are characterized by increased plasma levels of Ang-(17), reduced mean arterial pressure, and a blunted vasoconstrictive response following intra-arterial administration of Ang II, compared to SHRSP control rats. Furthermore, TGR(SM22ACE2) rats exhibit an improved vasodilatory response to acetylcholine, compared to SHR-SP control rats. These data suggest that vascular ACE2 overexpression in SHRSP rats reduces hypertension and improves endothelial function, perhaps via the ability of ACE2 to metabolize Ang II to Ang-(1-7).

\section{CONCLUSION}

The discovery of ACE2 and the generation of gene knockouts for this enzyme and for the receptor Mas have led to renewed interest in the role of Ang-(1-7) in renal pathophysiology. Ang-(1-7) regulates renal vascular tone and tubular transport, and affects signaling and growth in a cell-specific fashion. While evidence suggests that Ang-(1-7) is an endogenous vasodilator and may be protective in hypertensive renal injury, further studies are required to determine the impact of Ang-(1-7) on glomerular and tubular function in chronic pathophysiologic states, such as diabetic nephropathy.

\section{ACKNOWLEDGMENTS}

This work was supported by grants from the Canadian Institutes of Health Research and the Kidney Foundation of Canada (to KDB), and an Ontario Graduate Student Scholarship (to MD).

\section{REFERENCES}

1. Santos, R.A. and Ferreira, A.J. (2007) Angiotensin-(1-7) and the renin-angiotensin system. Curr. Opin. Nephrol. Hypertens. 16, 122-128.

2. Donoghue, M., Hsieh, F., Baronas, E., Godbout, K., Gosselin, M., Stagliano, N., Donovan, M., Woolf, B., Robison, K., Jeyaseelan, R., Breitbart, R.E., and Acton, S. (2000) A novel angiotensin-converting enzyme-related carboxypeptidase (ACE2) converts angiotensin I to angiotensin 1-9. Circ. Res. 87, E1-9.

3. Tipnis, S.R., Hooper, N.M., Hyde, R., Karran, E., Christie, G., and Turner, A.J. (2000) A human homolog of angiotensin-converting enzyme. Cloning and functional expression as a captopril-insensitive carboxypeptidase. $J$. Biol. Chem. 275, 33238-33243. 
4. Santos, R.A., Simoes e Silva, A.C., Maric, C., Silva, D.M., Machado, R.P., de Buhr, I., Heringer-Walther, S., Pinheiro, S.V., Lopes, M.T., Bader, M., Mendes, E.P., Lemos, V.S., Campagnole-Santos, M.J., Schultheiss, H.P., Speth, R., and Walther, T. (2003) Angiotensin-(1-7) is an endogenous ligand for the G protein-coupled receptor Mas. Proc. Natl. Acad. Sci. U. S. A. 100, 8258-8263.

5. Santos, R.A., Brosnihan, K.B., Jacobsen, D.W., DiCorleto, P.E., and Ferrario, C.M. (1992) Production of angiotensin-(1-7) by human vascular endothelium. Hypertension 19, II56-61.

6. Pendergrass, K.D., Pirro, N.T., Westwood, B.M., Ferrario, C.M., Brosnihan, K.B., and Chappell, M.C. (2008) Sex differences in circulating and renal angiotensins of hypertensive $\mathrm{mRen}(2)$.Lewis but not normotensive Lewis rats. Am. J. Physiol. Heart Circ. Physiol. 295, H10-20.

7. Pendergrass, K.D., Averill, D.B., Ferrario, C.M., Diz, D.I., and Chappell, M.C. (2006) Differential expression of nuclear AT1 receptors and angiotensin II within the kidney of the male congenic mRen2.Lewis rat. Am. J. Physiol. Renal Physiol. 290, F1497-1506.

8. Joyner, J., Neves, L.A., Granger, J.P., Alexander, B.T., Merrill, D.C., Chappell, M.C., Ferrario, C.M., Davis, W.P., and Brosnihan, K.B. (2007) Temporal-spatial expression of ANG-(1-7) and angiotensin-converting enzyme 2 in the kidney of normal and hypertensive pregnant rats. Am. J. Physiol. Regul. Integr. Comp. Physiol. 293, R169-177.

9. Erdos, E.G. and Skidgel, R.A. (1990) Renal metabolism of angiotensin I and II. Kidney Int. Suppl 30, S24-27.

10. Ferrario, C.M., Martell, N., Yunis, C., Flack, J.M., Chappell, M.C., Brosnihan, K.B., Dean, R.H., Fernandez, A., Novikov, S.V., Pinillas, C., and Luque, M. (1998) Characterization of angiotensin-(1-7) in the urine of normal and essential hypertensive subjects. Am. J. Hypertens. 11, 137-146.

11. Stephenson, S.L. and Kenny, A.J. (1987) Metabolism of neuropeptides. Hydrolysis of the angiotensins, bradykinin, substance $\mathrm{P}$ and oxytocin by pig kidney microvillar membranes. Biochem. J. 241, 237-247.

12. Trask, A.J. and Ferrario, C.M. (2007) Angiotensin-(1-7): pharmacology and new perspectives in cardiovascular treatments. Cardiovasc. Drug Rev. 25, 162-174.

13. Ward, P.E., Erdos, E.G., Gedney, C.D., Dowben, R.M., and Reynolds, R.C. (1976) Isolation of membrane-bound renal enzymes that metabolize kinins and angiotensins. Biochem. J. 157, 643-650.

14. Ward, P.E. and Sheridan, M.S. (1983) Converting enzyme, kininase and angiotensinase of renal and intestinal brush border. Adv. Exp. Med. Biol. 156(Pt B), 835-844.

15. Rice, G.I., Thomas, D.A., Grant, P.J., Turner, A.J., and Hooper, N.M. (2004) Evaluation of angiotensin-converting enzyme (ACE), its homologue ACE2 and neprilysin in angiotensin peptide metabolism. Biochem. J. 383, 45-51.

16. Brosnihan, K.B., Neves, L.A., Joyner, J., Averill, D.B., Chappell, M.C., Sarao, R., Penninger, J., and Ferrario, C.M. (2003) Enhanced renal immunocytochemical expression of ANG-(1-7) and ACE2 during pregnancy. Hypertension 42, 749-753.

17. Li, N., Zimpelmann, J., Cheng, K., Wilkins, J.A., and Burns, K.D. (2005) The role of angiotensin converting enzyme 2 in the generation of angiotensin 1-7 by rat proximal tubules. Am. J. Physiol. Renal Physiol. 288, F353-362.

18. Shaltout, H.A., Westwood, B.M., Averill, D.B., Ferrario, C.M., Figueroa, J.P., Diz, D.I., Rose, J.C., and Chappell, M.C. (2007) Angiotensin metabolism in renal proximal tubules, urine, and serum of sheep: evidence for ACE2dependent processing of angiotensin II. Am. J. Physiol. Renal Physiol. 292, F82-91.

19. Tikellis, C., Johnston, C.I., Forbes, J.M., Burns, W.C., Burrell, L.M., Risvanis, J., and Cooper, M.E. (2003) Characterization of renal angiotensin-converting enzyme 2 in diabetic nephropathy. Hypertension 41, 392-397.

20. Gurley, S.B., Allred, A., Le, T.H., Griffiths, R., Mao, L., Philip, N., Haystead, T.A., Donoghue, M., Breitbart, R.E., Acton, S.L., Rockman, H.A., and Coffman, T.M. (2006) Altered blood pressure responses and normal cardiac phenotype in ACE2-null mice. J. Clin. Invest. 116, 2218-2225.

21. Ye, M., Wysocki, J., William, J., Soler, M.J., Cokic, I., and Batlle, D. (2006) Glomerular localization and expression of Angiotensin-converting enzyme 2 and Angiotensin-converting enzyme: implications for albuminuria in diabetes. J. Am. Soc. Nephrol. 17, 3067-3075.

22. Lely, A.T., Hamming, I., van Goor, H., and Navis, G.J. (2004) Renal ACE2 expression in human kidney disease. $J$. Pathol. 204, 587-593.

23. Velez, J.C., Bland, A.M., Arthur, J.M., Raymond, J.R., and Janech, M.G. (2007) Characterization of reninangiotensin system enzyme activities in cultured mouse podocytes. Am. J. Physiol. Renal Physiol. 293, F398-407. Allred, A.J., Diz, D.I., Ferrario, C.M., and Chappell, M.C. (2000) Pathways for angiotensin-(1---7) metabolism in pulmonary and renal tissues. Am. J. Physiol. Renal Physiol. 279, F841-850. Chappell, M.C., Pirro, N.T., Sykes, A., and Ferrario, C.M. (1998) Metabolism of angiotensin-(1-7) by angiotensinconverting enzyme. Hypertension 31, 362-367.

26. Deddish, P.A., Marcic, B., Jackman, H.L., Wang, H.Z., Skidgel, R.A., and Erdos, E.G. (1998) N-domain-specific substrate and C-domain inhibitors of angiotensin-converting enzyme: angiotensin-(1-7) and keto-ACE. Hypertension 31, 912-917.

27. Santos, R.A., Campagnole-Santos, M.J., Baracho, N.C., Fontes, M.A., Silva, L.C., Neves, L.A., Oliveira, D.R., Caligiorne, S.M., Rodrigues, A.R., Gropen Junior, C., et al. (1994) Characterization of a new angiotensin antagonist selective for angiotensin-(1-7): evidence that the actions of angiotensin-(1-7) are mediated by specific angiotensin receptors. Brain Res. Bull. 35, 293-298.

28. Alenina, N., Xu, P., Rentzsch, B., Patkin, E.L., and Bader, M. (2008) Genetically altered animal models for Mas and angiotensin-(1-7). Exp. Physiol. 93, 528-537. 
29. Su, Z., Zimpelmann, J., and Burns, K.D. (2006) Angiotensin-(1-7) inhibits angiotensin II-stimulated phosphorylation of MAP kinases in proximal tubular cells. Kidney Int. 69, 2212-2218.

30. Chappell, M.C., Modrall, J.G., Diz, D.I., and Ferrario, C.M. (2004) Novel aspects of the renal renin-angiotensin system: angiotensin-(1-7), ACE2 and blood pressure regulation. Contrib. Nephrol. 143, 77-89.

31. Zimpelmann, J. and Burns, K.D. (2009) Angiotensin-(1-7) activates growth-stimulatory pathways in human mesangial cells. Am. J. Physiol. Renal Physiol. 296, F337-346.

32. Christensen, E.I. and Birn, H. (2002) Megalin and cubilin: multifunctional endocytic receptors. Nat. Rev. Mol. Cell Biol. 3, 256-266.

33. Gonzalez-Villalobos, R., Klassen, R.B., Allen, P.L., Johanson, K., Baker, C.B., Kobori, H., Navar, L.G., and Hammond, T.G. (2006) Megalin binds and internalizes angiotensin-(1-7). Am. J. Physiol. Renal Physiol. 290, F1270-1275.

34. Heitsch, H., Brovkovych, S., Malinski, T., and Wiemer, G. (2001) Angiotensin-(1-7)-Stimulated nitric oxide and superoxide release from endothelial cells. Hypertension 37, 72-76.

35. Brosnihan, K.B., Li, P., and Ferrario, C.M. (1996) Angiotensin-(1-7) dilates canine coronary arteries through kinins and nitric oxide. Hypertension 27, 523-528.

36. Muthalif, M.M., Benter, I.F., Uddin, M.R., Harper, J.L., and Malik, K.U. (1998) Signal transduction mechanisms involved in angiotensin-(1-7)-stimulated arachidonic acid release and prostanoid synthesis in rabbit aortic smooth muscle cells. J. Pharmacol. Exp. Ther. 284, 388-398.

37. Sampaio, W.O., Nascimento, A.A., and Santos, R.A. (2003) Systemic and regional hemodynamic effects of angiotensin-(1-7) in rats. Am. J. Physiol. Heart Circ. Physiol. 284, H1985-1994.

38. van der Wouden, E.A., Ochodnicky, P., van Dokkum, R.P., Roks, A.J., Deelman, L.E., de Zeeuw, D., and Henning, R.H. (2006) The role of angiotensin(1-7) in renal vasculature of the rat. J. Hypertens. 24, 1971-1978.

39. Ren, Y., Garvin, J.L., and Carretero, O.A. (2002) Vasodilator action of angiotensin-(1-7) on isolated rabbit afferent arterioles. Hypertension 39, 799-802.

40. Handa, R.K., Ferrario, C.M., and Strandhoy, J.W. (1996) Renal actions of angiotensin-(1-7): in vivo and in vitro studies. Am. J. Physiol. 270, F141-147.

41. Navar, L.G., Inscho, E.W., Majid, S.A., Imig, J.D., Harrison-Bernard, L.M., and Mitchell, K.D. (1996) Paracrine regulation of the renal microcirculation. Physiol. Rev. 76, 425-536.

42. Benter, I.F., Ferrario, C.M., Morris, M., and Diz, D.I. (1995) Antihypertensive actions of angiotensin-(1-7) in spontaneously hypertensive rats. Am. J. Physiol. 269, H313-319.

43. Dharmani, M., Mustafa, M.R., Achike, F.I., and Sim, M.K. (2007) Effects of angiotensin 1-7 on the actions of angiotensin II in the renal and mesenteric vasculature of hypertensive and streptozotocin-induced diabetic rats. Eur. J. Pharmacol. 561, 144-150.

44. Heller, J., Kramer, H.J., Maly, J., Cervenka, L., and Horacek, V. (2000) Effect of intrarenal infusion of angiotensin(1-7) in the dog. Kidney Blood Press. Res. 23, 89-94.

45. Andreatta-van Leyen, S., Romero, M.F., Khosla, M.C., and Douglas, J.G. (1993) Modulation of phospholipase A2 activity and sodium transport by angiotensin-(1-7). Kidney Int. 44, 932-936.

46. De Souza, A.M., Lopes, A.G., Pizzino, C.P., Fossari, R.N., Miguel, N.C., Cardozo, F.P., Abi-Abib, R., Fernandes, M.S., Santos, D.P., and Caruso-Neves, C. (2004) Angiotensin II and angiotensin-(1-7) inhibit the inner cortex Na+ ATPase activity through AT2 receptor. Regul. Pept. 120, 167-175.

47. Garcia, N.H. and Garvin, J.L. (1994) Angiotensin 1-7 has a biphasic effect on fluid absorption in the proximal straight tubule. J. Am. Soc. Nephrol. 5, 1133-1138.

48. Santos, R.A., Simoes e Silva, A.C., Magaldi, A.J., Khosla, M.C., Cesar, K.R., Passaglio, K.T., and Baracho, N.C. (1996) Evidence for a physiological role of angiotensin-(1-7) in the control of hydroelectrolyte balance. Hypertension 27, 875-884.

49. Joyner, J., Neves, L.A., Stovall, K., Ferrario, C.M., and Brosnihan, K.B. (2008) Angiotensin-(1-7) serves as an aquaretic by increasing water intake and diuresis in association with downregulation of aquaporin-1 during pregnancy in rats. Am. J. Physiol. Regul. Integr. Comp. Physiol. 294, R1073-1080.

50. Simoes e Silva, A.C., Bello, A.P., Baracho, N.C., Khosla, M.C., and Santos, R.A. (1998) Diuresis and natriuresis produced by long term administration of a selective Angiotensin-(1-7) antagonist in normotensive and hypertensive rats. Regul. Pept. 74, 177-184.

51. Joyner, J., Neves, L., Ferrario, C., and Brosnihan, K. (2008) Administration of D-alanine-[Ang-(1-7)] (A-779) prior to pregnancy in Sprague Dawley rats produces antidiuresis in late gestation. J. Am. Soc. Hypertens. 2, 425-430.

52. Ferreira, A.J., Pinheiro, S.V., Castro, C.H., Silva, G.A., Silva, A.C., Almeida, A.P., Bader, M., Rentzsch, B., Reudelhuber, T.L., and Santos, R.A. (2006) Renal function in transgenic rats expressing an angiotensin-(1-7)producing fusion protein. Regul. Pept. 137, 128-133.

53. Vallon, V., Richter, K., Heyne, N., and Osswald, H. (1997) Effect of intratubular application of angiotensin 1-7 on nephron function. Kidney Blood Press. Res. 20, 233-239.

54. Magaldi, A.J., Cesar, K.R., de Araujo, M., Simoes e Silva, A.C., and Santos, R.A. (2003) Angiotensin-(1-7) stimulates water transport in rat inner medullary collecting duct: evidence for involvement of vasopressin V2 receptors. Pflugers Arch. 447, 223-230. 
55. Pinheiro, S.V., Simoes e Silva, A.C., Sampaio, W.O., de Paula, R.D., Mendes, E.P., Bontempo, E.D., Pesquero, J.B., Walther, T., Alenina, N., Bader, M., Bleich, M., and Santos, R.A. (2004) Nonpeptide AVE 0991 is an angiotensin-(17) receptor Mas agonist in the mouse kidney. Hypertension 44, 490-496.

56. Yamada, K., Iyer, S.N., Chappell, M.C., Ganten, D., and Ferrario, C.M. (1998) Converting enzyme determines plasma clearance of angiotensin-(1-7). Hypertension 32, 496-502.

57. Holstein-Rathlou, N.H., Christensen, P., and Leyssac, P.P. (1982) Effects of halothane-nitrous oxide inhalation anesthesia and Inactin on overall renal and tubular function in Sprague-Dawley and Wistar rats. Acta Physiol. Scand. 114, 193-201.

58. Gava, E., Samad-Zadeh, A., Zimpelmann, J., Bahramifarid, N., Kitten, G.T., Santos, R.A., Touyz, R.M., and Burns, K.D. (2009) Angiotensin-(1-7) activates a tyrosine phosphatase and inhibits glucose-induced signalling in proximal tubular cells. Nephrol. Dial. Transplant. 24(6), 1766-1773.

59. Grobe, J.L., Mecca, A.P., Lingis, M., Shenoy, V., Bolton, T.A., Machado, J.M., Speth, R.C., Raizada, M.K., and Katovich, M.J. (2007) Prevention of angiotensin II-induced cardiac remodeling by angiotensin-(1-7). Am. J. Physiol. Heart Circ. Physiol. 292, H736-742.

60. Iwata, M., Cowling, R.T., Gurantz, D., Moore, C., Zhang, S., Yuan, J.X., and Greenberg, B.H. (2005) Angiotensin(1-7) binds to specific receptors on cardiac fibroblasts to initiate antifibrotic and antitrophic effects. Am. J. Physiol. Heart Circ. Physiol. 289, H2356-2363.

61. Grobe, J.L., Mecca, A.P., Mao, H., and Katovich, M.J. (2006) Chronic angiotensin-(1-7) prevents cardiac fibrosis in DOCA-salt model of hypertension. Am. J. Physiol. Heart Circ. Physiol. 290, H2417-2423.

62. Tallant, E.A., Ferrario, C.M., and Gallagher, P.E. (2005) Angiotensin-(1-7) inhibits growth of cardiac myocytes through activation of the mas receptor. Am. J. Physiol. Heart Circ. Physiol. 289, H1560-1566.

63. Kostenis, E., Milligan, G., Christopoulos, A., Sanchez-Ferrer, C.F., Heringer-Walther, S., Sexton, P.M., Gembardt, F., Kellett, E., Martini, L., Vanderheyden, P., Schultheiss, H.P., and Walther, T. (2005) G-protein-coupled receptor Mas is a physiological antagonist of the angiotensin II type 1 receptor. Circulation 111, 1806-1813.

64. Nie, W., Yan, H., Li, S., Zhang, Y., Yu, F., Zhu, W., Fan, F., and Zhu, J. (2009) Angiotensin-(1-7) enhances angiotensin II induced phosphorylation of ERK1/2 in mouse bone marrow-derived dendritic cells. Mol. Immunol. 46, $355-361$.

65. Heringer-Walther, S., Eckert, K., Schumacher, S.M., Uharek, L., Wulf-Goldenberg, A., Gembardt, F., Fichtner, I., Schultheiss, H.P., Rodgers, K., and Walther, T. (2009) Angiotensin-(1-7) stimulates hematopoietic progenitor cells in vitro and in vivo. Haematologica 94, 857-860.

66. Yamamoto, K., Ohishi, M., Katsuya, T., Ito, N., Ikushima, M., Kaibe, M., Tatara, Y., Shiota, A., Sugano, S., Takeda, S., Rakugi, H., and Ogihara, T. (2006) Deletion of angiotensin-converting enzyme 2 accelerates pressure overloadinduced cardiac dysfunction by increasing local angiotensin II. Hypertension 47, 718-726.

67. Oudit, G.Y., Herzenberg, A.M., Kassiri, Z., Wong, D., Reich, H., Khokha, R., Crackower, M.A., Backx, P.H., Penninger, J.M., and Scholey, J.W. (2006) Loss of angiotensin-converting enzyme-2 leads to the late development of angiotensin II-dependent glomerulosclerosis. Am. J. Pathol. 168, 1808-1820.

68. Walther, T., Voigt, J.P., Fink, H., and Bader, M. (2000) Sex specific behavioural alterations in Mas-deficient mice. Behav. Brain Res. 107, 105-109.

69. Santos, R.A., Castro, C.H., Gava, E., Pinheiro, S.V., Almeida, A.P., Paula, R.D., Cruz, J.S., Ramos, A.S., Rosa, K.T., Irigoyen, M.C., Bader, M., Alenina, N., Kitten, G.T., and Ferreira, A.J. (2006) Impairment of in vitro and in vivo heart function in angiotensin-(1-7) receptor MAS knockout mice. Hypertension 47, 996-1002.

70. Pinheiro, S.V., Ferreira, A.J., Kitten, G.T., da Silveira, K.D., da Silva, D.A., Santos, S.H., Gava, E., Castro, C.H., Magalhaes, J.A., da Mota, R.K., Botelho-Santos, G.A., Bader, M., Alenina, N., Santos, R.A., and Simoes e Silva, A.C. (2009) Genetic deletion of the angiotensin-(1-7) receptor Mas leads to glomerular hyperfiltration and microalbuminuria. Kidney Int. 75, 1184-1193.

71. Esteban, V., Heringer-Walther, S., Sterner-Kock, A., de Bruin, R., van den Engel, S., Wang, Y., Mezzano, S., Egido, J., Schultheiss, H.P., Ruiz-Ortega, M., and Walther, T. (2009) Angiotensin-(1-7) and the g protein-coupled receptor MAS are key players in renal inflammation. PLOS ONE 4, e5406.

72. Xu, P., Costa-Goncalves, A.C., Todiras, M., Rabelo, L.A., Sampaio, W.O., Moura, M.M., Santos, S.S., Luft, F.C., Bader, M., Gross, V., Alenina, N., and Santos, R.A. (2008) Endothelial dysfunction and elevated blood pressure in MAS gene-deleted mice. Hypertension 51, 574-580.

73. Soldatos, G. and Cooper, M.E. (2008) Diabetic nephropathy: important pathophysiologic mechanisms. Diabetes Res. Clin. Pract. 82(Suppl 1), S75-79.

74. Hostetter, T.H., Rennke, H.G., and Brenner, B.M. (1982) The case for intrarenal hypertension in the initiation and progression of diabetic and other glomerulopathies. Am. J. Med. 72, 375-380.

75. Ye, M., Wysocki, J., Naaz, P., Salabat, M.R., LaPointe, M.S., and Batlle, D. (2004) Increased ACE 2 and decreased ACE protein in renal tubules from diabetic mice: a renoprotective combination? Hypertension 43, 1120-1125.

76. Mizuiri, S., Hemmi, H., Arita, M., Ohashi, Y., Tanaka, Y., Miyagi, M., Sakai, K., Ishikawa, Y., Shibuya, K., Hase, H., and Aikawa, A. (2008) Expression of ACE and ACE2 in individuals with diabetic kidney disease and healthy controls. Am. J. Kidney Dis. 51, 613-623.

77. Reich, H.N., Oudit, G.Y., Penninger, J.M., Scholey, J.W., and Herzenberg, A.M. (2008) Decreased glomerular and tubular expression of ACE2 in patients with type 2 diabetes and kidney disease. Kidney Int. 74, 1610-1616. 
78. Soler, M.J., Wysocki, J., Ye, M., Lloveras, J., Kanwar, Y., and Batlle, D. (2007) ACE2 inhibition worsens glomerular injury in association with increased ACE expression in streptozotocin-induced diabetic mice. Kidney Int. 72, 614-623.

79. Wong, D.W., Oudit, G.Y., Reich, H., Kassiri, Z., Zhou, J., Liu, Q.C., Backx, P.H., Penninger, J.M., Herzenberg, A.M., and Scholey, J.W. (2007) Loss of angiotensin-converting enzyme-2 (Ace2) accelerates diabetic kidney injury. Am. J. Pathol. 171, 438-451.

80. Benter, I.F., Yousif, M.H., Dhaunsi, G.S., Kaur, J., Chappell, M.C., and Diz, D.I. (2008) Angiotensin-(1-7) prevents activation of NADPH oxidase and renal vascular dysfunction in diabetic hypertensive rats. Am. J. Nephrol. 28, 2533.

81. Benter, I.F., Yousif, M.H., Cojocel, C., Al-Maghrebi, M., and Diz, D.I. (2007) Angiotensin-(1-7) prevents diabetesinduced cardiovascular dysfunction. Am. J. Physiol. Heart Circ. Physiol. 292, H666-672.

82. Shao, Y., He, M., Zhou, L., Yao, T., Huang, Y., and Lu, L.M. (2008) Chronic angiotensin (1-7) injection accelerates STZ-induced diabetic renal injury. Acta Pharmacol. Sin. 29, 829-837.

83. Ji, H., Menini, S., Zheng, W., Pesce, C., Wu, X., and Sandberg, K. (2008) Role of angiotensin-converting enzyme 2 and angiotensin(1-7) in 17beta-oestradiol regulation of renal pathology in renal wrap hypertension in rats. Exp. Physiol. 93, 648-657.

84. Luque, M., Martin, P., Martell, N., Fernandez, C., Brosnihan, K.B., and Ferrario, C.M. (1996) Effects of captopril related to increased levels of prostacyclin and angiotensin-(1-7) in essential hypertension. J. Hypertens. 14, 799-805.

85. Kohara, K., Brosnihan, K.B., Chappell, M.C., Khosla, M.C., and Ferrario, C.M. (1991) Angiotensin-(1-7). A member of circulating angiotensin peptides. Hypertension 17, 131-138.

86. Kohara, K., Brosnihan, K.B., and Ferrario, C.M. (1993) Angiotensin(1-7) in the spontaneously hypertensive rat. Peptides 14, 883-891.

87. Campbell, D.J., Lawrence, A.C., Towrie, A., Kladis, A., and Valentijn, A.J. (1991) Differential regulation of angiotensin peptide levels in plasma and kidney of the rat. Hypertension 18, 763-773.

88. Walters, P.E., Gaspari, T.A., and Widdop, R.E. (2005) Angiotensin-(1-7) acts as a vasodepressor agent via angiotensin II type 2 receptors in conscious rats. Hypertension 45, 960-966.

89. Iyer, S.N., Chappell, M.C., Averill, D.B., Diz, D.I., and Ferrario, C.M. (1998) Vasodepressor actions of angiotensin(1-7) unmasked during combined treatment with lisinopril and losartan. Hypertension 31, 699-705.

90. Iyer, S.N., Ferrario, C.M., and Chappell, M.C. (1998) Angiotensin-(1-7) contributes to the antihypertensive effects of blockade of the renin-angiotensin system. Hypertension 31, 356-361.

91. Rentzsch, B., Todiras, M., Iliescu, R., Popova, E., Campos, L.A., Oliveira, M.L., Baltatu, O.C., Santos, R.A., and Bader, M. (2008) Transgenic angiotensin-converting enzyme 2 overexpression in vessels of SHRSP rats reduces blood pressure and improves endothelial function. Hypertension 52, 967-973.

\section{This article should be cited as follows:}

Dilauro, M. and Burns, K.D. (2009) Angiotensin-(1-7) and its effects in the kidney. TheScientificWorldJOURNAL 9, $522-535$. DOI 10.1100/tsw.2009.70. 

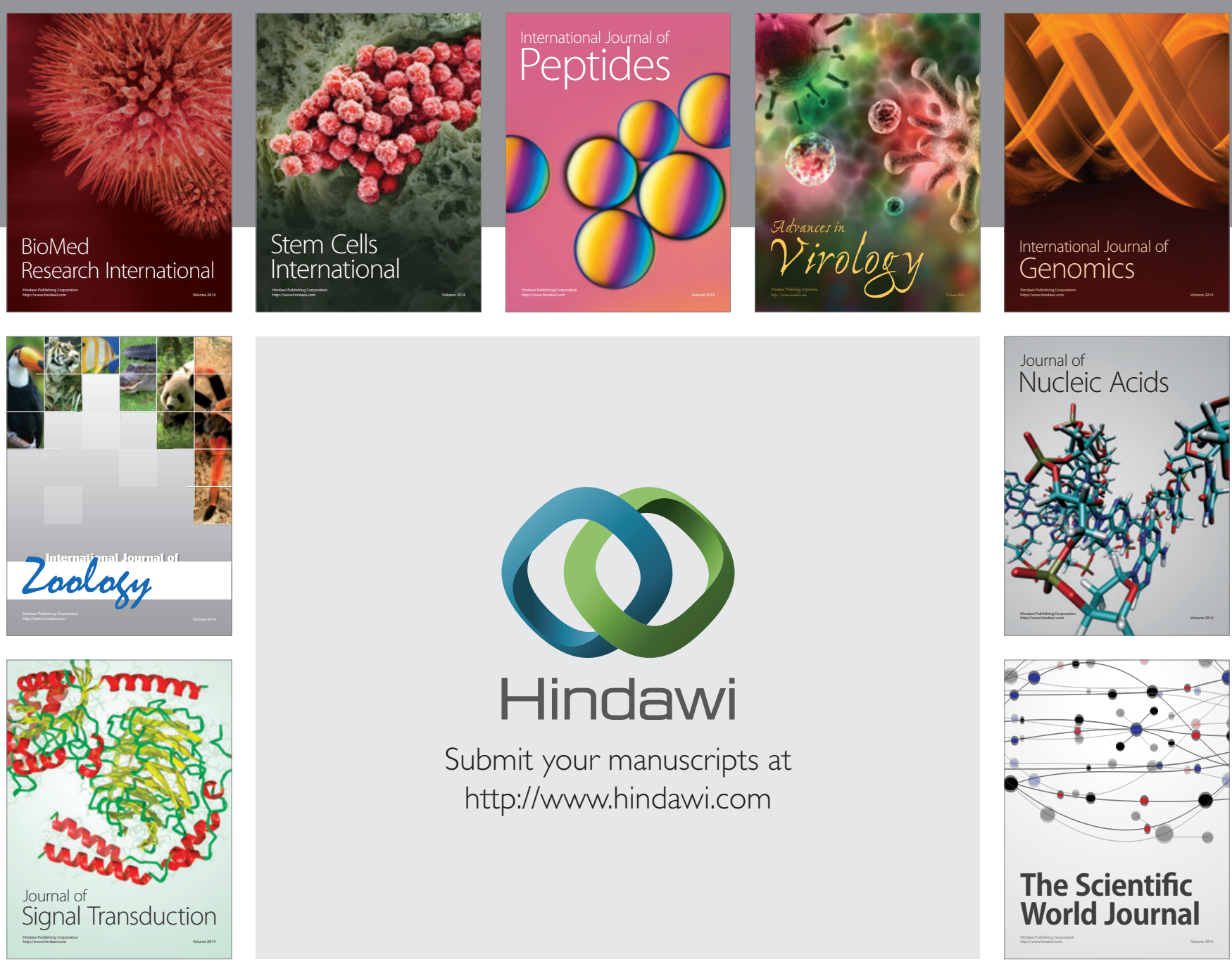

Submit your manuscripts at

http://www.hindawi.com
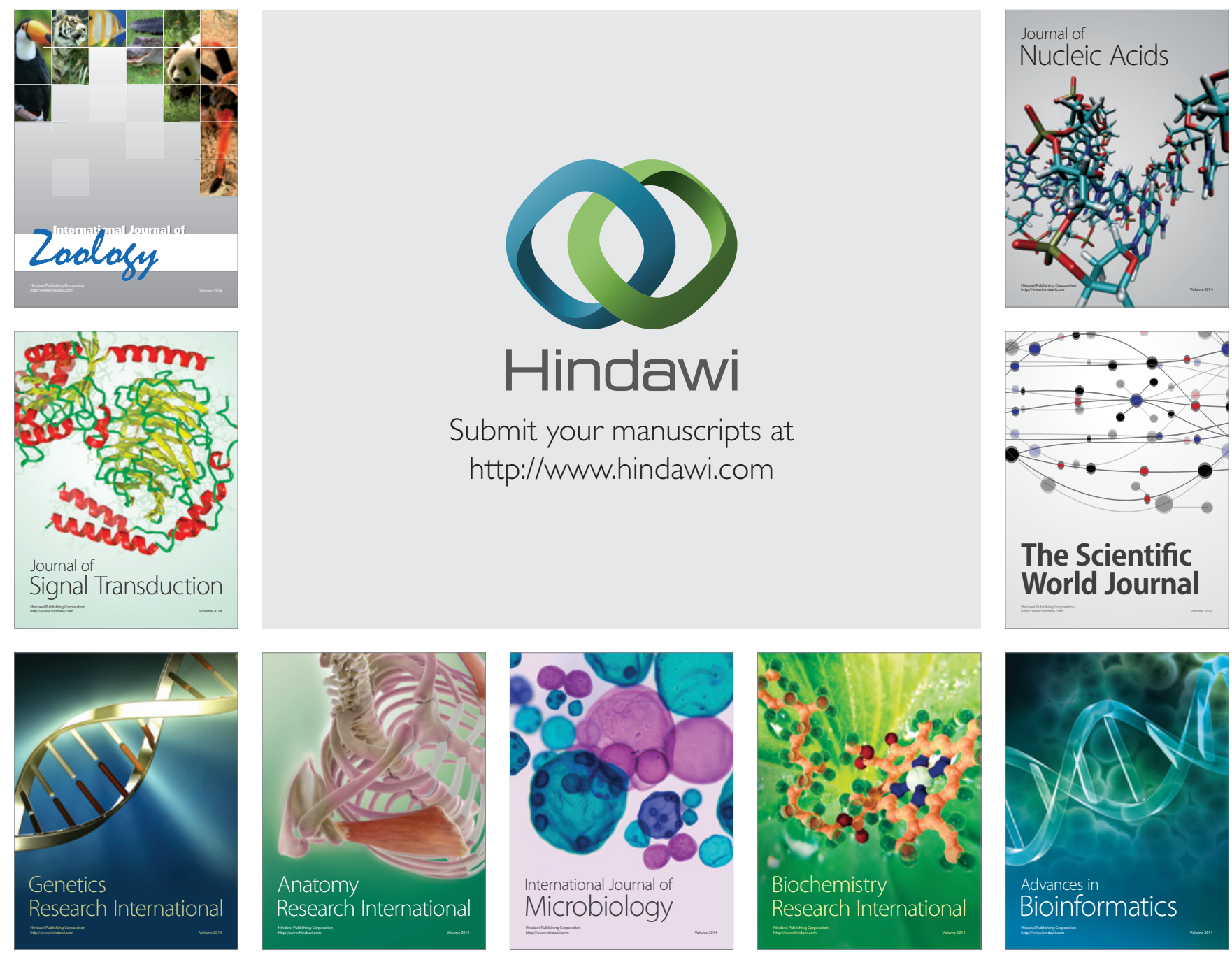

The Scientific World Journal
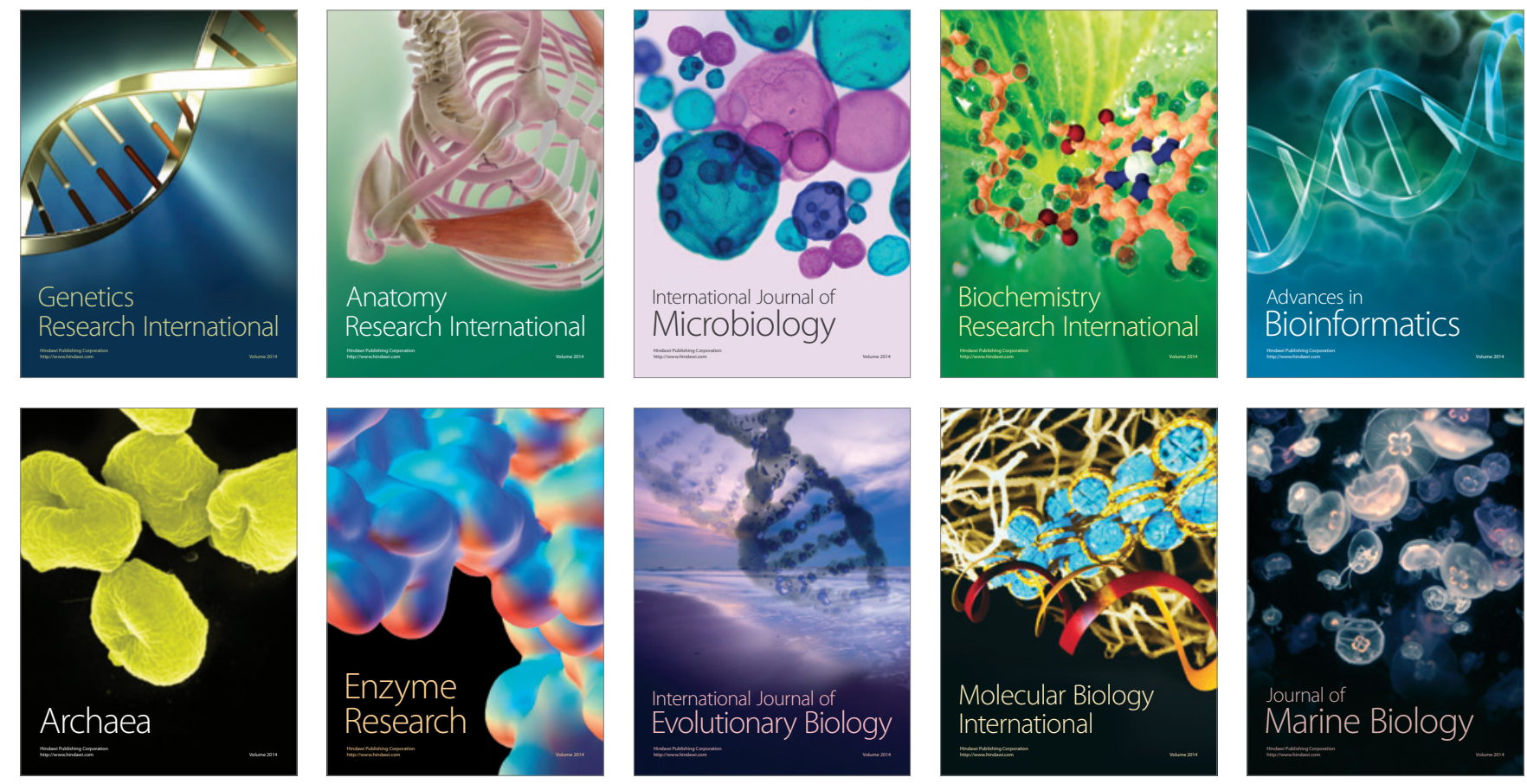